\title{
La excepción preliminar falta de agotamiento de recursos internos y su relación con el fondo del caso*
}

\author{
Recibido: 21 de diciembre de 2017 • Aprobado: 11 de julio de 2018 \\ https://doi.org/10.22395/ojum.v18n36a8 \\ Andrés González Serrano ** \\ Jesús Eduardo Sanabria Moyano*** \\ Cindy Tatiana Merchán López****
}

\begin{abstract}
RESUMEN
El artículo recoge el estudio de las sentencias de excepciones preliminares y de fondo de la Corte Interamericana de Derechos Humanos (Corte IDH) entre los años 2010 a 2016, en las cuales examinó y desestimó la excepción preliminar "falta de agotamiento de recursos internos" (fari) interpuesta por los Estados partes, para luego declarar la responsabilidad internacional por la violación a los derechos humanos a las garantías judiciales y protección judicial, con el fin de identificar la interacción entre estas dos decisiones. El cumplimiento de dicho objetivo se consiguió a partir de una investigación cualitativa, básica y jurídica, que utiliza el método analítico deductivo e inductivo, y centra su análisis -como fuente principal- en la jurisprudencia de la Corte Internacional de Derechos Humanos, mediante la creación de una línea jurisprudencial. Se pudo encontrar que la dicha corte no aplica un criterio unificado para realizar la unión de la excepción con el fondo del asunto, aunque a partir de la interpretación de sus decisiones se identifica una interacción de los pronunciamientos que hace tanto en la excepción preliminar como en el fondo.

Palabras clave: Corte Interamericana de Derechos Humanos; falta de agotamiento de recursos internos; garantías judiciales; protección judicial.
\end{abstract}

Este artículo es producto del proyecto INV-DER 2057 Excepción preliminar falta de agotamiento de los recursos internos y su relación con los derechos humanos a las garantías y protección judicial. Una mirada desde la Corte Interamericana correspondiente al grupo de Derecho Público, línea de investigación sobre Derechos Humanos y Derecho Internacional Humanitario que se adelanta en el Centro de Investigaciones Jurídicas, Políticas y Sociales de la Facultad de Derecho de la Universidad Militar Nueva Granada. Proyecto financiado por la Vicerrectoría de Investigaciones de la Universidad Militar Nueva Granada, vigencia 2016.

** Abogado Magna Cum Laude de la Universidad Militar Nueva Granada, Colombia, especialista en Docencia Universitaria y magíster en Derecho Administrativo de la Universidad Militar Nueva Granada, magíster en Protección Internacional de Derechos Humanos de la Universidad de Alcalá, España, candidato a Doctor en la Universidad de Alcalá, España. Profesor investigador del grupo de Derecho Público y de la línea de Derechos Humanos y Derecho Internacional Humanitario del Centro de Investigaciones Jurídicas, Políticas y Sociales de la Facultad de Derecho de la Universidad Militar Nueva Granada, Colombia. Correo electrónico: andres.gonzalez@ unimilitar.edu.co y gonzalezserranoandres@gmail.com. Orcid: https://orcid.org/0000-0001-6185-426X

*** Abogado de la Universidad Militar Nueva Granada, Colombia, especialista en Derechos Humanos y Derecho Internacional Humanitario aplicado a los Conflictos Armados de la Escuela de Derechos Humanos y Derecho Internacional Humanitario del Ejército Nacional, Colombia, magíster en Derecho Público Militar de la Universidad Militar Nueva Granada, Colombia. Profesor investigador del grupo de Derecho Público y de la línea de Derechos Humanos y Derecho Internacional Humanitario del Centro de Investigaciones Jurídicas, Políticas y Sociales de la Facultad de Derecho de la Universidad Militar Nueva Granada. Correo electrónico: jesus.sanabria@unimilitar.edu.co y jesuseduardosanabria@gmail.com. Orcid: https://orcid. org/0000-0001-9715-5305

**** Abogada de la Universidad Militar Nueva Granada, Colombia, especialista en Derecho Administrativo de Universidad Militar Nueva Granada. Joven investigadora del grupo de Derecho Público y de la línea de Derechos Humanos y Derecho Internacional Humanitario del Centro de Investigaciones Jurídicas, Políticas y Sociales de la Facultad de Derecho de la Universidad Militar Nueva Granada. Correo electrónico: tmp.cindy.merchan@ unimilitar.edu.co y tatamlopez@gmail.com. 


\title{
The "Non-exhaustion of domestic remedies" preliminary objection and its relationship with the merits of the case
}

\begin{abstract}
This paper presents a study on the merits and preliminary objection judgements of the Inter-American Court of Human Rights between 2010 and 2016, in which the "Nonexhaustion of domestic remedies" preliminary objection filed by the States Parties was dismissed, and after that the Court determined the international liability for the violation of judicial guarantees and judicial protection rights, in order to identify an interaction between these actions. This goal was achieved through a qualitative, legal, and basic research using the deductive and inductive analytical method. The analysis focuses on the jurisprudence of the Inter-American Court of Human Rights through the creation of a line of case-law. It was found that the aforementioned Court does not apply a unified approach to make a link between objection and merits, even though by means of interpreting its decisions an interaction between its statements on both preliminary objections and merits is identified.
\end{abstract}

Keywords: Inter-American Court of Human Rights; non-exhaustion of domestic remedies; legal guarantees; judicial protection.

\section{A exceção preliminar da falta de esgotamento de recursos internos e sua relação com o fundo do caso}

\begin{abstract}
RESUMO
O artigo trabalha com o estudo as sentenças de exceções preliminares e de fundo da Corte Interamericana de Direitos Humanos (Corte IDH) entre os anos de 2010 a 2016, nas quais examinou e desestimou a exceção preliminar da "falta de esgotamento de recursos internos" interposta pelos Estados-Partes para, em seguida, declarar a responsabilidade internacional pela violação dos direitos humanos às garantias judiciais e à proteção judicial, com o fim de identificar a interação entre essas duas decisões. O cumprimento de tal objetivo foi alcançado a partir de uma pesquisa qualitativa, básica e jurídica, que utiliza o método analítico dedutivo e indutivo, e centra sua análise — como fonte principal — na jurisprudência da Corte IDH, por meio da criação de uma linha jurisprudencial. Foi possível descobrir que a Corte IDH não aplica um critério unificado para realizar a união da exceção com o fundo do assunto, ainda que a partir da interpretação de suas decisões seja identificada uma interação dos pronunciamentos que faz tanto na exceção preliminar quanto no fundo.

Palavras-chave: Corte Interamericana de Direitos Humanos; falta de esgotamento de recursos internos; garantias judiciais; proteção judicial.
\end{abstract}




\section{INTRODUCCIÓN}

El artículo es producto del proyecto titulado Excepción preliminar falta de agotamiento de los recursos internos y su relación con los derechos humanos a las garantías y protección judicial. Una mirada desde la Corte Interamericana, y tiene como finalidad examinar los criterios jurisprudenciales señalados por la Corte IDH para declarar que los recursos internos mencionados por los Estados a través de la excepción preliminar, no cumplen con el estándar convencional y, por lo tanto, su análisis es remitido al fondo del asunto para concluir con el incumplimiento y la responsabilidad internacional por las violaciones a los derechos humanos de las garantías judiciales y de la protección judicial.

En relación con el agotamiento de los recursos internos, la Convención Americana sobre Derechos Humanos, en el artículo 46.1.a señala que es un requisito de procedibilidad de una petición o comunicación para que sea declarada admisible, es decir que las víctimas o sus representantes debieron haber interpuesto y agotado los recursos con los que cuenta la jurisdicción interna, conforme a los principios del derecho internacional generalmente reconocidos (Corte Internacional de Justicia, 1959; OEA. Convención Americana,1969; Corte IDH, 1990; Faúndez, 2007; González, 2010). Entre ellos el de subsidiariedad y complementariedad de los sistemas internacionales de protección, porque permite al Estado denunciado conocer la situación jurídica infringida de los derechos humanos y resolverlo conforme al derecho interno antes de verse enfrentado a un proceso internacional (Santana y de la Muela, 1978; Paúl, 2015).

Sin embargo, la misma Convención Americana en el artículo 46.2, establece tres excepciones a esta regla en favor de las víctimas, a saber, que:

a) no exista en la legislación interna del Estado de que se trata, el debido proceso legal para la protección del derecho o derechos que se alega han sido violados;

b) no se haya permitido al presunto lesionado en sus derechos el acceso a los recursos de la jurisdicción interna, o haya sido impedido de agotarlos, y

c) haya retardo injustificado en la decisión sobre los mencionados recursos (OEA. Convención Americana, 1969).

Por esta razón, uno de los mecanismos de defensa jurídica con los que cuenta el Estado parte de la Convención, sujeto a un procedimiento cuasi-jurisdiccional de la Comisión Interamericana, es la excepción preliminar falta de agotamiento de los recursos internos. En dicho evento, corresponde al órgano hacer un detallado análisis del alegato planteado y determinar si los recursos con los que cuenta el Estado, efectivamente dan mérito para declarar inadmisible la petición, por no cumplir con este requisito 
convencional de admisibilidad a cargo de las víctimas o sus representantes (Trindade, 1991; Barbosa, 2002; Faúndez, 2004; CIDH, 2009; 2017).

De igual forma, dicha excepción preliminar se podrá interponer ante la Corte Interamericana, siempre y cuando se cumplan con los siguientes requisitos de procedibilidad fijados por ella misma en su jurisprudencia (González, 2010). En primer lugar, ha determinado que la excepción debe ser presentada en el momento procesal oportuno (Corte IDH, 1987a), es decir, en la etapa de admisibilidad ante la Comisión Interamericana, y en caso de no haberse hecho será entendido como una renuncia tácita a la misma (Corte IDH, 2007). En segundo lugar, el Estado debe indicar los recursos adecuados y efectivos que debieron agotar las víctimas en sede interna, antes de acudir a la Comisión Interamericana (Corte IDH, 1987a; 2008a; 2012d). Finalmente, el Estado no podrá interponerla si en una actuación anterior realizó una renuncia tácita o expresa frente a la excepción (Corte IDH, 1996; 2002).

En este orden de ideas, en caso de que la excepción preliminar interpuesta por el Estado cumpla con los requisitos de procedibilidad para ser estudiada en instancia de la Corte Interamericana, esta entrará a analizar si los recursos alegados en la excepción son los adecuados y efectivos para garantizar los derechos infringidos. De igual forma, verifica si las presuntas víctimas tenían o no el deber de agotar la jurisdicción interna bajo las reglas y las excepciones del artículo 46 Convencional (González, Sanabria y Meléndez, 2018).

De igual forma, el agotamiento de los recursos internos implica para el Estado la obligación de proporcionar los recursos judiciales adecuados y efectivos para garantizar el libre y pleno ejercicio de los derechos humanos contenidos en la Convención Americana (Corte IDH, 1987a; 1987b; Faúndez, 2007). Dicha obligación constituye uno de los pilares básicos fundamentales del propio Estado de Derecho en una sociedad democrática (Corte IDH, 1996; 2002). Por tanto, cuando una víctima o su representante demuestran que no se encontraban obligados a agotar los recursos internos bajo las excepciones del artículo 46.2, implica que la Corte IDH desestime la excepción propuesta por el Estado y de paso identifique la existencia del incumplimiento de las obligaciones de respeto y garantía en conexidad con los derechos humanos a las garantías y protección judicial:

Los Estados Partes se obligan a suministrar recursos judiciales efectivos a las víctimas de violación de los derechos humanos (art. 25), recursos que deben ser sustanciados de conformidad con las reglas del debido proceso legal (art. 8.1), todo ello dentro de la obligación general a cargo de los mismos Estados, de garantizar el libre y pleno ejercicio de los derechos reconocidos por la Convención a toda persona que se encuentre bajo su jurisdicción (art. 1) (Corte IDH. 1987b, párr. 90). 
Lo anterior evidencia una relación entre la excepción de falta de agotamiento de los recursos internos con los derechos humanos a las garantías judiciales y protección judicial, los cuales deben ser estudiados en el análisis de fondo, etapa procesal donde se analiza la responsabilidad internacional del Estado denunciado (Corte IDH, 1996; 1998; 1999; 2005a; 2005b; 2006; 2007; 2008a; 2008b; 2009a; 2009b).

Por consiguiente, el artículo pretende desarrollar la anterior hipótesis e identificar los elementos que hacen la interacción de la excepción preliminar de falta de agotamiento de los recursos internos y el fondo del asunto relacionados con los derechos a las garantías judiciales y protección judicial, bajo el método de análisis jurisprudencial (López, 2008), con la creación de la línea jurisprudencial que responderá a la siguiente pregunta ¿Existe relación entre la desestimación de la excepción FARI por factores de procedibilidad y la responsabilidad internacional del Estado por la violación a los derechos humanos a las garantías y protección judicial?, con la cual, se busca responder a la hipótesis planteada y de paso identificar los espacios de interacción entre las etapas del análisis de forma y fondo.

La construcción de la línea jurisprudencial surge del análisis jurisprudencial de las sentencias de excepciones preliminares y fondo proferidas por la Corte Interamericana de Derechos Humanos entre los años 2010 a 2016, en específico de los casos en los que la Corte IDH desestimó la excepción preliminar por factores que se pueden presentar en el proceso de esta ante el sistema interamericano, como son la falta del cumplimiento de los requisitos procesales y de los reconocimientos de responsabilidad de los Estados, con los cuales se esperaría que es evidente la interacción y de paso la declaración de responsabilidad.

Por lo anterior, los espacios convencionales se presentan de la siguiente forma: en primer lugar, se analizan los casos en los que la Corte Interamericana ha desestimado la excepción preliminar planteada por el Estado en razón a los requisitos de procedibilidad. Posteriormente, se hace un estudio de los casos en los que ha presentado un reconocimiento de responsabilidad por parte del Estado por el incumplimiento de las obligaciones convencionales, frente a la violación de los derechos humanos a las garantías judiciales y protección judicial.

\section{RESULTADOS}

\subsection{Desestima la excepción FARI por requisitos de procedibilidad}

En el siguiente espacio convencional se describen los casos relacionados con la desestimación de la excepción preliminar FARI, en razón del incumplimiento de los requisitos de procedibilidad que la Corte IDH exige para interponer dicha excepción ante su instancia. 
El primer caso, objeto de estudio es Chocrón Chocrón vs. Venezuela, en el cual el Estado interpuso la excepción preliminar bajo este argumento: que la supuesta víctima omitió interponer el recurso de revisión ante la Sala Constitucional del Tribunal Supremo de Justicia, lo que le hubiera permitido tener la posibilidad de anular la decisión de la Sala Político Administrativa emitida en su contra (Corte IDH, 2011a).

Al respecto, la Corte IDH identificó el incumplimiento de la obligación por parte del Estado de indicar oportunamente los recursos internos demostrando su respectiva efectividad, por tanto, la excepción fue declarada improcedente porque no le corresponde a la Corte IDH subsanar la falta de precisión de los alegatos del Estado (2011a).

En el fondo del caso, la Corte IDH reiteró que las autoridades deben respetar las garantías del debido proceso en toda decisión sujeta a su competencia y constató que la designación que se le hizo a la señora Chocrón Chocrón, quedó sin efectos por unos argumentos cuyo contenido y naturaleza nunca fueron precisados (2011a). Entonces, la Corte IDH declaró la responsabilidad del Estado por la violación a las garantías judiciales, al constatar que el deber de motivar las decisiones internas no fue respetada ni garantizada.

Frente a la alegada violación de la protección judicial, la Corte IDH señaló que el Estado se había abstenido de examinar el recurso contencioso administrativo sobre la destitución argumentando que la Comisión Judicial tenía la potestad tanto para designar como para dejar sin efectos la designación de los jueces, cuando así fuera precisado por la mayoría de sus miembros (2011a). Por lo tanto, la Corte IDH, evidenció la falta de aplicación del principio de independencia judicial, al ser el mismo órgano el que decide la destitución y a su vez el recurso en segunda instancia, lo que constata la falta de garantías al derecho humano de protección judicial (201la).

De igual forma, declaró internacionalmente responsable al Estado por el incumplimiento a la obligación de adopción de las disposiciones de derecho interno contenidas en el artículo 2 de la Convención, por la inexistencia de normas expresas frente a la remoción de jueces provisorios y temporales, lo que generaba un margen de arbitrariedad que impedía garantizar la independencia judicial reconocida en los artículos 8.1 y 25.1 de la Convención (Corte IDH, 2011a).

En este orden de ideas, este caso no evidencia una interacción entre el análisis que hace la Corte IDH de la excepción de falta de agotamiento de los recursos internos con la violación a las garantías judiciales y a la protección judicial, ya que en la etapa preliminar analizó el recurso de revisión ante la Sala Constitucional del Tribunal Supremo de Justicia para decir que dicho recurso no fue alegado de manera oportuna. Y, en el fondo del asunto, la Corte IDH no se pronunció respecto a este recurso, sino 
que entró a analizar y a declarar las violaciones frente a otros procedimientos que surtieron internamente respecto de la destitución, lo que confirma que, aun cuando la Corte IDH identifica desde la etapa preliminar la inexistencia de los recursos de forma directa, dicho resultado no es criterio de decisión para declarar el incumplimiento y violación de los derechos objeto de estudio.

En 2012, la Corte IDH conoció el caso González Medina y familiares vs. República Dominicana, en el cual el Estado interpuso la excepción de falta de agotamiento de los recursos internos, argumentando que era imposible que, en el transcurso de 35 días contados entre la desaparición del señor González y la presentación de la petición ante la Comisión, los recursos en sede interna fueran agotados. De igual forma señaló que las excepciones contenidas en el artículo 46 numeral 2 de la Convención no eran aplicables al caso. Finalmente, adicionó que desde el momento procesal oportuno había interpuesto la excepción y que las presuntas víctimas tenían a disposición cinco recursos internos que debían ser agotados, sin embargo, en la sentencia no fueron detallados (2012a).

Al respecto, la Corte IDH reiteró que la excepción debe ser presentada en el momento procesal oportuno, que corresponde al Estado indicar qué recursos deben agotarse y la efectividad de los mismos, esto porque no solo debe mencionar la existencia formal de los recursos. Por tanto, determinó que los alegatos presentados por el Estado en la contestación de la demanda no se interpusieron de forma adecuada ante la Comisión y desestimó la excepción (2012a).

En el fondo del asunto, la Corte IDH, al analizar las violaciones alegadas, recordó que la obligación de investigar debe ser asumida por el Estado, con la finalidad de evitar la impunidad y la repetición de los hechos (2012a). Frente al caso, la investigación estuvo a cargo del Estado, la cual tuvo una duración de siete años y seis meses sin obtener resultados favorables para las víctimas. Luego se realizó la reapertura de la misma sin lograr ningún resultado al momento de la sentencia, con el agravante de que las violaciones a los derechos humanos eran atribuibles a un agente estatal. Por tanto, evaluó la Corte IDH que la actividad procesal por parte de los familiares de la presunta víctima fue constante, pero por parte de la autoridad judicial no fue suficiente, concluyendo que las investigaciones a cargo del juzgado de instrucción, de la cámara de calificación y del Ministerio Público excedieron el plazo razonable, y que se violaron así los derechos humanos a las garantías judiciales y a la protección judicial.

En este caso se logra identificar una relación entre la excepción preliminar y el análisis de fondo. Porque en esta etapa se tomó en cuenta el recurso de acción penal para declarar las violaciones a los derechos humanos de garantías judiciales y protección judicial, considerándola como un recurso inefectivo y demostrado la falta del 
cumplimiento de los parámetros y estándares de la debida investigación. Por tanto, se logra evidenciar una interacción entre los dos análisis que hace la Corte IDH, porque estudia el mismo recurso en la desestimación de la excepción y en el fondo del asunto.

En el año 2014, se estudió el caso hermanos Landaeta Mejías y otros vs. Venezuela, la excepción de la falta de agotamiento de los recursos internos fue interpuesta por el Estado indicando la existencia de un proceso penal pendiente de la Corte de Apelaciones del Circuito Judicial Penal del Estado de Aragua. Además, los peticionarios disponían de un recurso de revisión y casación en caso de que la primera instancia resultara desfavorable. Por tanto, las víctimas, al no interponer los recursos frente a la actuación en el proceso penal, permitieron que se declarara la suspensión (Corte IDH, 2014b).

Por su parte, la Corte IDH reiteró que la regla del previo agotamiento de los recursos internos está concebida en interés del Estado. Sin embargo, debe indicar en el momento procesal oportuno los recursos internos que no se agotaron y demostrar que se encontraban disponibles, que eran adecuados, idóneos y efectivos para la situación. Como dicho requisito de procedibilidad no se logró evidenciar, la Corte IDH desestimó la excepción por ser presentada de forma extemporánea (Corte IDH, 2014b).

En el fondo del caso, la Corte IDH señaló que los Estados están obligados a proveer recursos judiciales efectivos los cuales deben ser sustanciados de conformidad con las reglas del debido proceso. En específico, evaluó el proceso penal y la investigación cursada por la muerte de los hermanos Landaeta, en la cual identificó como falencias: a) la ausencia de líneas lógicas y conjuntas de investigación por ser los mismos patrones de conducta; b) el deber de investigar la muerte de una persona en custodia del Estado y c) la existencia de presuntas irregularidades y omisiones en las diligencias iniciales de la investigación (Corte IDH, 2014b).

Además, respecto al cumplimiento del plazo razonable, determinó que existieron serios retrasos procesales e irregularidades ocasionadas por las propias autoridades judiciales internas, que no tuvieron como fin esclarecer los hechos ni sancionar a los responsables, lo que permitió la impunidad en el caso, por lo que declaró responsable al Estado por la violación de los derechos de garantías judicial y protección judicial en relación con la obligación del artículo 1.1 de la Convención en perjuicio de la familia Landaeta (Corte IDH, 2014b).

En este caso, al existir incumplimiento de los requisitos de procedibilidad de la excepción de falta de agotamiento de los recursos internos, no se logra identificar un análisis detallado de los recursos propuestos por el Estado. Sin embargo, en el análisis de fondo dichos recursos son estudiados, en específico, la acción penal, para deter- 
minar que no es el mecanismo efectivo para la protección de los derechos humanos objeto del litigio, argumento por el cual se declaró la responsabilidad internacional y la violación a los derechos humanos a las garantías judiciales y protección judicial. En consecuencia, se logra identificar una interacción indirecta entre la excepción preliminar por el recurso alegado por el Estado y el análisis de la Corte IDH en la etapa de fondo.

Posteriormente, la Corte IDH conoció el caso de los pueblos indígenas Kuna de Madungandí y Emberá de Bayano y sus miembros vs. Panamá. En esta oportunidad, el Estado interpuso la excepción de falta de agotamiento de los recursos internos manifestando que la había incoado en reiteradas ocasiones ante la Comisión, señalando los recursos adecuados y efectivos relacionados con la solicitud de indemnizaciones. Para ello, citaba el artículo 97 de la sección $5^{\text {a }}$ del Código Judicial el cual desarrollaba la competencia de la Sala Tercera de lo Contencioso Administrativo para temas del pago de indemnizaciones por responsabilidad del Estado e hizo referencia a una serie de recursos que se encontraban disponibles, entre ellos: i) la acción de inconstitucionalidad, ii) la jurisdicción contenciosa administrativa, iii) acciones y recursos en todas las instancias de vías administrativas y judiciales, iv) amparo de garantías constitucionales y v) recurrir a la Defensoría del Pueblo (Corte IDH, 2014c).

Ante lo cual, la Corte IDH aceptó que el Estado había interpuesto la excepción durante el trámite ante la Comisión e hizo referencia de los recursos que debieron agotarse, pero, en dicha oportunidad, no hizo la precisión sobre cuáles de los recursos mencionados eran idóneos y efectivos para el pago de las indemnizaciones. Por lo que rechazó la excepción relacionada con la presunta falta de pago de las indemnizaciones al no haberse interpuesto en el momento procesal oportuno de forma precisa y específica (Corte IDH, 2014c).

En el análisis de fondo, la Corte IDH consideró que los recursos incoados frente a la solicitud de adjudicación en algunos casos no fueron atendidos por las autoridades y, en otros, no contaron con una respuesta que permitiera la adecuada determinación de sus derechos y obligaciones, por lo que la Corte IDH declaró responsable al Estado por la violación a los derechos humanos a las garantías y protección judicial (2014c). De igual forma, la duración excesiva de los procedimientos penales y administrativos relacionados con la solicitud de lanzamiento en contra de los ocupantes, configuró un incumplimiento de la garantía del plazo razonable y, por tanto, la violación al derecho humano de las garantías judiciales (2014c).

En este caso, no se logra identificar la interacción que existe entre los recursos estudiados en la etapa preliminar con el fondo del caso, en virtud a que la Corte IDH desestimó la excepción por el requisito procesal de presentación en tiempo, y en el 
fondo del asunto, al momento de decidir las violaciones alegadas, analizó los procesos penales y el proceso administrativo respecto de la adjudicación y la efectividad del proceso, mas no de los recursos que podían ser idóneos para las indemnizaciones, propuestos por el Estado como mecanismos adecuados y efectivos de la excepción preliminar de falta de agotamiento de los recursos internos.

Ahora bien, en el caso Galindo Cárdenas y otros vs. Perú, los agentes estatales interpusieron la excepción preliminar alegando la existencia de recursos idóneos en la jurisdicción interna como: i) el habeas corpus, en razón de la detención alegada, ii) el amparo, en cuanto a la presunta aplicación indebida de la Ley de Arrepentimiento, iii) recursos impugnatorios, para cuestionar las decisiones fiscales, iv) denuncia penal contra aquellas autoridades que estuvieron involucradas en los supuestos hechos lesivos y v) proceso civil de indemnización por daños y perjuicios (Corte IDH, 2015e).

En este sentido, la Corte IDH desestimó la excepción preliminar de falta de agotamiento de los recursos internos porque el Estado no había cumplido con la carga de demostrar en el momento procesal oportuno la idoneidad y efectividad de los recursos mencionados (2015e). Sin embargo, realizó un detallado análisis del recurso de habeas corpus, en el que logró evidenciar la imposibilidad de interponerlo por la falta de garantías, debido a situaciones fácticas y jurídicas existentes al momento de los hechos (2015e).

En la etapa del fondo, la Corte IDH analizó el incumplimiento de la obligación de investigar de manera oficiosa y diligente la reclusión del peticionario en una base militar, donde sufrió tortura psicológica y física por el aislamiento, lo que configuró una actuación contraria a las obligaciones convencionales y violatoria de los derechos humanos a las garantías y protección judicial (2015e).

Por tanto, como resultado del análisis de este caso, se logró identificar que no existe una interacción entre la excepción preliminar propuesta por el Estado, con la amplia gama de recursos internos alegados, que en su momento fueron desestimados por no especificar que eran adecuados y efectivos para la situación jurídica infringida. Elementos que debieron haber sido analizados en la etapa de fondo para determinar la responsabilidad del Estado por la violación de los derechos a las garantías judiciales y protección judicial, pero no fue así, porque la Corte IDH en este acápite se limitó a estudiar el recurso de la investigación penal, criterio que no fue objeto de análisis en la excepción preliminar.

A su turno, en el caso López Lone y otros Vs. Honduras, el Estado interpuso la excepción preliminar, indicando que no se habían agotado los recursos de i) demanda 
contenciosa administrativa, la cual tenía como objeto el reintegro o pago de indemnizaciones y ii) de amparo como recurso idóneo para la protección de los derechos humanos (Corte IDH, 2015f).

Teniendo en cuenta lo anterior, la Corte IDH identificó que el recurso propuesto de la jurisdicción contencioso administrativo era extemporáneo y lo desestimó. Respecto al recurso de amparo, a pesar de que fue alegado en el momento procesal oportuno, existía una norma interna que impedía interponer dicho recurso contra las resoluciones del Consejo de la Carrera judicial. Sin embargo, el Estado aportó diferentes precedentes de acciones de amparo contra las decisiones emitidas por dicho órgano, pero no fueron suficientes para demostrar que era el recurso adecuado y efectivo, porque no era viable tener la certeza de la posibilidad de interponer dicha acción, y ante la incertidumbre, no se podía exigir a las víctimas agotar dicho recurso como requisito de admisibilidad. Por lo tanto, la excepción respecto del recurso de amparo también fue desestimada (2015f).

Al analizar las violaciones alegadas en el fondo del caso, la Corte IDH determinó que las cuatro víctimas fueron sujetas a procesos disciplinarios que no estaban previstos legalmente, lo que conllevó a que fueran juzgadas por un tribunal sin competencia, con falta de imparcialidad y falta de independencia, violando las garantías judiciales (2015f).

Respecto a la violación de la protección judicial, la Corte IDH señaló que el recurso de amparo era inefectivo frente a las decisiones en los procedimientos disciplinarios a los que fueron sometidos los peticionarios por la imposibilidad de interponerlos, por ello declaró responsable internacionalmente al Estado (2015f).

En esta oportunidad, se puede identificar la interacción que existe en la etapa preliminar y en el fondo del caso respecto del recurso de amparo, el cual fue desestimado por la Corte IDH al no ser demostrada en la etapa procesal oportuna que era adecuado y efectivo. Decisión que fue fundamento para declarar el incumplimiento de las obligaciones convencionales de respeto y garantía en conexidad con el derecho humano de protección judicial en la etapa del fondo.

Posteriormente, se analizó el caso Maldonado Ordóñez vs. Guatemala, donde el Estado interpuso la excepción preliminar indicando la existencia de recursos en la jurisdicción interna sin agotar la acción ordinaria laboral (Corte IDH, 2016), y agregó que el uso inadecuado de los recursos internos configuraba la falta de agotamiento de estos, porque al no utilizar las acciones judiciales internas con las características de adecuadas y efectivas, no podría considerarse por cumplido el deber convencional para las víctimas (Corte IDH, 2016), así pues, la Corte IDH indicó que, si bien la excepción había sido planteada en la etapa de admisibilidad ante la Comisión, los argumentos 
referentes a la efectividad de vía ordinaria laboral resultaban extemporáneos y por ello desestimó la excepción preliminar (2016).

En la etapa de fondo, al analizar las violaciones alegadas en relación con las garantías judiciales, la Corte IDH identificó que a la víctima no se le suministró información sobre: i) la motivación del proceso de destitución y ii) la sanción disciplinaria y la norma supuestamente infringida, evidenciando una violación a la garantía judicial de una comunicación previa y detallada al inculpado de la acusación formulada. De igual forma, señaló que la falta de claridad de los cargos imputados no permitió a la señora Maldonado contar con los mecanismos para fundamentar su defensa, y se le violó el derecho humano de las garantías judiciales de la Convención Americana (Corte IDH, 2016).

Respecto a la alegada violación al derecho humano de protección judicial, la Corte IDH determinó que existió una contradicción en la normativa interna respecto del recurso que debía ser interpuesto y, a pesar de incoar los recursos que estaban contemplados en el Reglamento de Personal del Procurador, estos no fueron efectivos para poder revisar la decisión de su destitución. Por lo que la confusión y contradicción en la normativa interna puso a la peticionaria en una situación de desprotección al no tener acceso efectivo al recurso que permitiera garantizar el derecho de protección judicial. Por lo anterior, la Corte IDH declaró la violación a este derecho humano en conexidad con el deber de adoptar disposiciones de derecho interno contenidas en el artículo 2 de la Convención Americana (2016).

En el presente caso, no se logra evidenciar una interacción entre la excepción preliminar y el fondo del asunto. La Corte IDH desestimó por criterios de procedibilidad la excepción fundamentada en el recurso de la jurisdicción laboral. Sin embargo, dicho recurso fue tenido en cuenta en la etapa del análisis de fondo, pues el objeto de la controversia se refiere a que la víctima no tenía la posibilidad de accionar un recurso al existir contradicciones en la normatividad interna, lo que generó la responsabilidad del Estado por la violación al derecho a la protección judicial.

De los anteriores casos se logra identificar que la relación entre la excepción preliminar falta de agotamiento de los recursos internos, cuando es desestimada por requisitos de procedibilidad, y el fondo del asunto cuando se analiza la responsabilidad por las violaciones a los derechos humanos de garantías judiciales y protección judicial, no se presenta de forma directa sino que su relación depende de si el recurso alegado por el Estado es considerado por la Corte IDH como adecuado para la situación jurídica infringida, en dicho evento será objeto de estudio para determinar las violaciones en el fondo del asunto. De lo contrario, así el Estado mencione una serie 
de recursos, estos no serán tenidos en cuenta en el análisis de fondo y no se logrará evidenciar la interacción entre las dos etapas procesales.

\subsection{Desestima la excepción y existe un reconocimiento de responsabilidad}

En el presente capítulo se examinan los casos en los cuales la Corte IDH ha desestimado la excepción preliminar de falta de agotamiento de los recursos internos porque el Estado ha presentado un reconocimiento de responsabilidad por el incumplimiento de las obligaciones convencionales en relación con la violación a los derechos humanos de garantías judiciales y protección judicial.

En primer lugar, se estudió el caso Vélez Loor vs. Panamá en el que el Estado interpuso la excepción preliminar de falta de agotamiento de los recursos internos, indicando que el peticionario no había agotado los recursos existentes en la jurisdicción interna para reclamar sus derechos, entre ellos, señaló los recursos de: i) reconsideración y apelación, ii) revisión administrativa, iii) protección de los Derechos Humanos, iv) la acción de Amparo de Garantías Constitucionales y v) la acción de habeas corpus. De igual forma resaltó que estos recursos eran efectivos y estaban al alcance del peticionario. Frente a la presunta violación y a los actos de tortura, argumentó que el señor Vélez Loor no había interpuesto denuncia o queja al respecto, a pesar de haber tenido acceso a medios y oportunidades para hacerlo (Corte IDH, 2010).

Por su parte, la Corte IDH, identificó que el Estado no había sido claro ni explícito al momento de interponer la excepción durante el trámite de admisibilidad ante la Comisión, ni había detallado los recursos como lo estaba haciendo ante la Corte IDH (2010). De igual forma, determinó que el Estado había hecho un reconocimiento parcial de responsabilidad internacional, donde admitió que no se le notificó al señor Vélez Loor el contenido de la Resolución 7306 de 2002, lo que conllevó a la sanción por dos años de prisión sin la garantía del derecho a la defensa. Situación que la Corte IDH consideró incompatible porque la excepción propuesta por el Estado alegaba la falta de agotamiento de unos recursos que surgían de la debida notificación de la resolución, sobre la cual el Estado había hecho el reconocimiento de responsabilidad (2010), por lo anterior, declara la excepción extemporánea y en consecuencia la desestima.

Al analizar el fondo del asunto, la Corte IDH estudió el procedimiento llevado a cabo ante la Dirección Nacional de Migración y determinó que dentro de la legislación interna no existía una reglamentación específica para este, por lo que se recurrió a suplirlo mediante un acto administrativo sancionatorio que fue decidido sin que el señor Vélez Loor haya sido oído, ni tuviese la posibilidad de ejercer el derecho a la defensa como garantía del debido proceso, privándolo de su libertad (2010), por lo 
que declaró internacionalmente responsable al Estado por el incumplimiento de las obligaciones convencionales y los derechos a las garantías y protección judicial.

En relación con la asistencia consular, la Corte IDH evidenció que, si bien el señor Vélez Loor tuvo comunicación y recibió visitas de funcionarios consulares de Ecuador, estas se hicieron con el fin de entregarle implementos de aseo personal, dinero en efectivo, medicinas y la solicitud de médicos que verificaran las condiciones de salud del señor Vélez Loor, más no para materializar la asistencia consular como parte del debido proceso, dado que el procedimiento administrativo sancionatorio se decidió sin ser oída la parte afectada, lo que significó el incumplimiento internacional del Estado y consecuencia la violación al derecho humano de garantías judiciales (2010).

En cuanto al hecho reconocido por el Estado, relativo al no haber notificado la resolución emitida por la Dirección Nacional de Migración, la Corte IDH indicó que la violación del derecho de defensa del señor Vélez Loor se debió a la imposibilidad de recurrir el fallo sancionatorio, resaltando que es obligación de los Estados adoptar las medidas necesarias para garantizar un efectivo e igualitario acceso a la justicia. Por tanto, la Corte IDH consideró que el Estado incumplió su obligación de garantizar, sin discriminación, el derecho humano de protección judicial en perjuicio del señor Vélez Loor (2010).

En este caso, lo que llevó a la Corte Interamericana a desestimar la excepción de falta de agotamiento de los recursos internos fue el reconocimiento parcial de responsabilidad que hizo el Estado, así como la presentación extemporánea de una serie de recursos que no fueron alegados oportunamente, lo que evidencia que fue desestimada desde factores procedimentales, mas no por un estudio de los recursos propuestos por el Estado. Y respecto del fondo, la Corte IDH estudió los procesos tramitados internamente y señaló que la víctima no contó con asistencia consular y la respectiva notificación de la resolución de la Dirección Migratoria. Por lo que se logra evidenciar una relación indirecta, porque en la etapa de fondo, la Corte IDH recoge el hecho por el cual el Estado presenta su reconocimiento de responsabilidad y lo incluye dentro de los criterios para declarar el incumplimiento convencional de las obligaciones de respeto y garantía en conexidad con los derechos humanos a las garantías y protección judicial.

Posteriormente, en 2012, se presenta el caso masacre de Santo Domingo vs. Colombia, en el cual el Estado interpuso la excepción del previo agotamiento de los recursos internos haciendo referencia a las solicitudes de reparación de las personas que no agotaron los recursos internos ante la jurisdicción contencioso administrativa colombiana, siendo la adecuada para obtener la declaratoria de responsabilidad del Estado y la reparación integral de los perjuicios (Corte IDH, 2012d). 
La Corte IDH señaló que los argumentos del Estado respecto del proceso contencioso administrativo podían ser relevantes en la calificación y definición de la responsabilidad estatal, al igual que las pretensiones en el marco de una reparación integral, es por esto, que indicó que si bien, la reparación ante el Consejo de Estado no era un recurso que necesariamente debiera ser agotado, era relevante analizarlo en los casos que ha sido interpuesta por las víctimas o sus familiares en la búsqueda de una justa indemnización. Por ello, determinó que el análisis de este recurso podía corresponder al fondo del caso y desestimó la excepción interpuesta por el Estado (2012d). En el fondo del caso, el Estado realizó un reconocimiento por la violación a los derechos de garantías judiciales y protección judicial. Sin embargo, la Corte IDH determinó que se habían realizado numerosas y efectivas diligencias de investigación y no se encontró responsabilidad por parte del Estado en conexidad con estos derechos mencionados (2012d).

Por lo cual, no se evidencia una relación directa entre la desestimación de la excepción preliminar y el fondo del asunto, aun cuando el Estado hizo un reconocimiento de responsabilidad, la Corte IDH valoró las actuaciones diligentes del Estado en materia de investigación y no declaró responsabilidad internacional de Colombia a pesar de que en el análisis de la excepción preliminar se constata la inefectividad del recurso de reparación por vía contencioso administrativa para las víctimas.

A su turno, en el caso de la Corte Suprema de Justicia (Quintana Coello y otros vs. Ecuador), el Estado interpuso la excepción falta de agotamiento de los recursos internos, argumentando que las presuntas víctimas no agotaron el recurso de inconstitucionalidad, un recurso sencillo de agotar, el cual era idóneo y tenía como objetivo la revocación del acto impugnado y la anulación de sus efectos. También alegó, que el recurso contencioso-administrativo podía ser interpuesto por cualquier persona natural y jurídica (Corte IDH, 2013b).

Respecto a la excepción interpuesta, la Corte IDH señaló que, conforme al reconocimiento parcial de responsabilidad de los derechos a las garantías judiciales y protección judicial, el Estado había aceptado la plena competencia de la Corte IDH para conocer del mismo y por ello la excepción resultaba incompatible con el reconocimiento y no procede a analizarla (2013b).

Ahora bien, en fondo del asunto, la Corte IDH señaló que los magistrados de la Corte Suprema fueron destituidos mediante una resolución del Congreso Nacional que no tenía competencia para hacerlo, aplicando errónea y arbitrariamente una disposición legal. También determinó que los peticionarios no tuvieron oportunidad de ser oídos y fueron juzgados por un órgano que no era competente, por lo que declaró que el Estado violó las garantías judiciales (2013b). Frente a la acción de inconstitucionalidad, 
la Corte IDH aceptó el reconocimiento de responsabilidad del Estado respecto de la inefectividad del recurso por la falta de acceso a interponerlo (2013b).

En relación con el derecho humano a la protección judicial, y conforme al reconocimiento de responsabilidad que hizo el Estado de este derecho en audiencia pública, la Corte IDH aceptó el allanamiento, precisando que la inexistencia de un recurso judicial efectivo contra actos violatorios de los derechos humanos protegidos por la Convención en perjuicio de las víctimas constituía una violación flagrante a la protección judicial (2013b).

En este sentido, se logra identificar la existencia de la interacción entre la excepción preliminar por el recurso alegado como idóneo y su análisis en la etapa de fondo, aunque exista de por medio una actuación procesal excluyente del análisis de la competencia e inadmisibilidad del caso, generada a partir del reconocimiento de responsabilidad del Estado. Aun así, la Corte IDH se toma el espacio de analizar el recurso de la acción de inconstitucionalidad en el fondo del asunto, para corroborar y apoyar la decisión del Estado en su reconocimiento de responsabilidad en relación con la violación a los derechos humanos de las garantías judiciales y protección judicial.

Otro caso objeto de estudio, es el de Cruz Sánchez y otros vs. Perú, en el cual el Estado manifestó ante la Corte IDH, que había interpuesto la excepción preliminar oportunamente ante la Comisión y señaló que no había sido debidamente fundamentada la supuesta vulneración al plazo razonable alegado por las presuntas víctimas. Además, señaló la existencia de otro proceso penal por el delito de homicidio calificado que se encontraba en trámite y dentro de un plazo razonable (Corte IDH, 2015a).

La Corte IDH al analizar la excepción preliminar, indicó que en el año 2011 el Estado había reconocido parcialmente la responsabilidad por la vulneración del plazo razonable en el proceso judicial llevado a cabo en el fuero penal, y señaló que cuando una parte ha adoptado una actitud que redunda en deterioro propio o en beneficio de la contraria, no puede posteriormente, en virtud del principio de estoppel, asumir otra conducta que sea contradictoria con la primera. Es por esto que la Corte IDH determinó que el Estado no podía asumir otra posición, o contradecir la responsabilidad reconocida y como consecuencia desestimó la excepción preliminar (2015a).

En el fondo del asunto, la Corte IDH consideró que existieron irregularidades en el manejo de la escena de los hechos, en el levantamiento de los cadáveres, en la realización de las necropsias y, como consecuencia, las primeras diligencias y el aseguramiento del material probatorio carecieron de mínima confiabilidad. De igual forma, señaló que los procesos no se desarrollaron en un plazo razonable como tampoco fue probado por el Estado el haber realizado las diligencias necesarias para el 
proceso, además del previo reconocimiento parcial de responsabilidad. Por lo cual, la Corte IDH declaró responsable al Estado por la violación a los derechos humanos de garantías judiciales y protección judicial (2015a).

En esta oportunidad, la existencia de un reconocimiento de responsabilidad del Estado en relación con los derechos humanos de las garantías judiciales y protección judicial, es tenido en cuenta por la Corte IDH para desestimar la excepción y declarar la admisibilidad del caso, debido a que carecería de fundamento proponer una excepción preliminar cuando ya se tiene un reconocimiento de la responsabilidad, además del cambio de argumento en las diferentes etapas del proceso en el trámite ante los órganos del Sistema Interamericano. Pero, en el fondo del asunto, la Corte IDH analiza los recursos propuestos en la excepción preliminar como lo fue el proceso penal, para constatar el incumplimiento de las obligaciones convencionales y las violaciones a los derechos humanos. Lo anterior, evidencia una interacción directa entre las dos etapas en lo que respecta al recurso de investigación penal.

Seguidamente, en el caso de la Comunidad Campesina de Santa Bárbara vs. Perú, el Estado interpuso la excepción de falta de agotamiento de los recursos internos alegando que la petición fue interpuesta ante la Comisión Interamericana a los 21 días de sucedidos los hechos, cuando no se habían agotado los mecanismos de la jurisdicción nacional, agregando que a la fecha en que se presentó la denuncia ante la Comisión aún estaba en curso el inicio de las investigaciones (2015d).

Al respecto, la Corte IDH señaló que no se podía limitar, contradecir o vaciar de contenido el reconocimiento previo de responsabilidad que había hecho el Estado, e indicó que en el caso que se declarara procedente la excepción preliminar, se sustraerían todos los hechos y violaciones que fueron reconocidas en su momento por el Estado. Así mismo, indicó que el mismo, no había manifestado el por qué los recursos alegados eran adecuados, idóneos y efectivos, por ello desestimó la excepción preliminar (2015d).

Respecto al análisis de fondo y de las violaciones alegadas a los derechos a las garantías y protección judiciales, la Corte IDH consideró que el Estado: i) incurrió en una falta de debida diligencia en las primeras actuaciones de la investigación, ii) obstaculizó la debida investigación del caso en al menos seis formas distintas, iii) incurrió en faltas en la recaudación de prueba y la ubicación y captura de reos prófugos, así como en una demora prolongada en el esclarecimiento de todos los hechos del caso y la determinación del paradero de las víctimas desaparecidas tras la reapertura de la investigación del caso en la jurisdicción ordinaria, y iv) violó el derecho a conocer la verdad de los familiares de las quince víctimas desaparecidas del caso $(2015 \mathrm{~d})$. 
En el presente caso, nuevamente la Corte IDH insiste en las implicaciones que representan jurídicamente para los Estados hacer un reconocimiento de responsabilidad, como lo es aceptar la competencia de ella para que conozca del fondo del caso. Sin embargo, ello no es óbice para que la Corte IDH realice un análisis detallado en el fondo del asunto, recogiendo los alegatos de la excepción preliminar para declarar la responsabilidad internacional del Estado por los derechos humanos a las garantías y protección judicial, en específico a la investigación y al tratamiento de los procesos penales internos, lo que permite evidenciar la existencia de una interacción entre la excepción y el fondo del asunto.

El siguiente caso objeto de estudio es Velásquez Paiz y otros, en el cual, el Estado de Guatemala interpuso la excepción preliminar de falta de agotamiento de los recursos internos, indicando que los hechos se encontraban aún bajo investigación en el marco de un proceso penal. Además, señaló que dentro de la legislación interna existían recursos para garantizar el debido proceso que tenían que agotarse como mecanismo para promover e impulsar los diferentes procesos judiciales. También alegó que las presuntas víctimas no se le había negado el acceso a la justicia ni se había vulnerado el plazo razonable, pues el caso era un asunto complejo (Corte IDH, 2015g).

En relación con lo anterior, la Corte IDH identificó que el Estado había realizado un reconocimiento parcial e implícito de responsabilidad al momento en que fue interpuesta la petición, porque los recursos de la jurisdicción interna sufrían de retardos injustificados o falta de efectividad. Adicional a esto, determinó que el mismo no había indicado oportunamente cuáles recursos debían haber sido previamente agotados, ni demostró que estos fueran adecuados, idóneos y efectivos, en razón a esto desestimó la excepción preliminar (2015g).

En el fondo del asunto, la Corte IDH consideró que el Estado no realizó una investigación efectiva frente al asesinato de Claudina Velásquez Paíz como una posible manifestación de violencia de género, donde se evidenciaban estereotipos y prejuicios por los cuales se consideró a la víctima como una persona cuya muerte no era necesario investigar. En consecuencia, trascurridos 10 años de su homicidio aún se encontraba en total impunidad, lo que evidenciaba el vencimiento de todo plazo razonable, declarando al Estado responsable internacionalmente por la violación a los derechos a las garantías judiciales y a la protección judicial (2015g).

Por tanto, se logra identificar la interacción entre el recurso alegado en la etapa preliminar como lo es el de la investigación en la jurisdicción ordinaria de lo penal, el cual fue desestimado por la Corte IDH al no ser demostrada su idoneidad y efectividad por parte del Estado. Por tanto, la Corte IDH en el análisis de fondo se toma el papel de estudiar este recurso a la luz de los lineamientos y estándares de la investigación 
que ha otorgado el sistema interamericano, para endilgar la responsabilidad del Estado por el incumplimiento de las obligaciones convencionales y los derechos a las garantías judiciales y protección judicial.

En virtud de los casos anteriormente estudiados, se logra identificar que la actuación procesal de presentar un reconocimiento de responsabilidad internacional parte del Estado, implica en las decisiones de la Corte IDH, una interacción entre las dos etapas de forma y fondo. Aunque no hay razón para analizar los criterios alegados por parte del Estado en la excepción preliminar de falta de agotamiento de los recursos internos porque, de entrada, se reconoce la competencia y admisibilidad del caso. La Corte IDH analiza los recursos interpuestos en etapa preliminar para complementar y declarar la responsabilidad internacional del Estado por las violaciones a las garantías judiciales y protección judicial.

Aunque el caso de la masacre de Santo Domingo se sale de dicho escenario, y en la línea jurisprudencial se identifica por ser una decisión arquimédica, en la que se desestima la excepción preliminar, existe reconocimiento por parte del Estado y la Corte IDH no declara la responsabilidad por las violaciones a las garantías judiciales y protección judicial porque identificó que se habían realizado numerosas y efectivas diligencias de investigación para determinar la verdad de los hechos (Corte IDH, 2012d). Teniendo en cuenta los casos analizados, la línea jurisprudencial construida sería como se ve en la siguiente tabla.

Tabla 1. Línea jurisprudencial

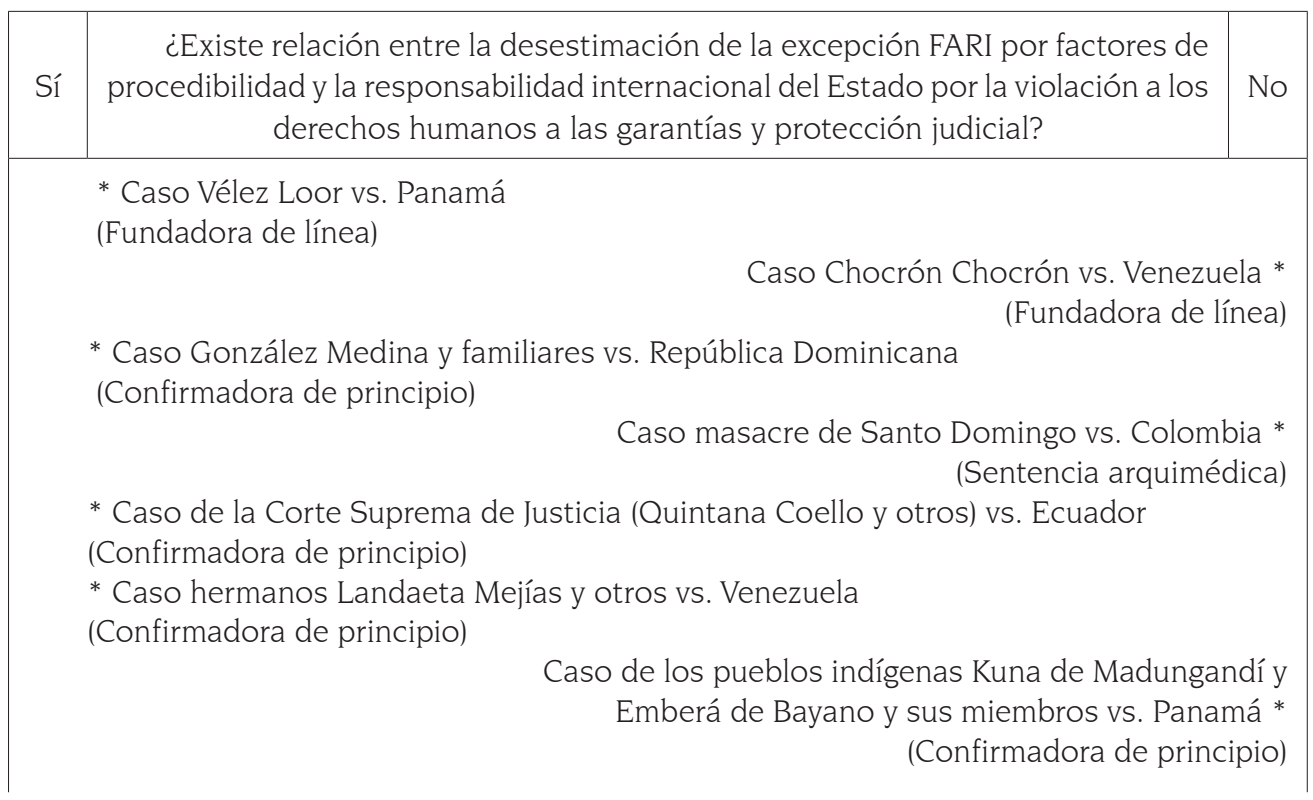




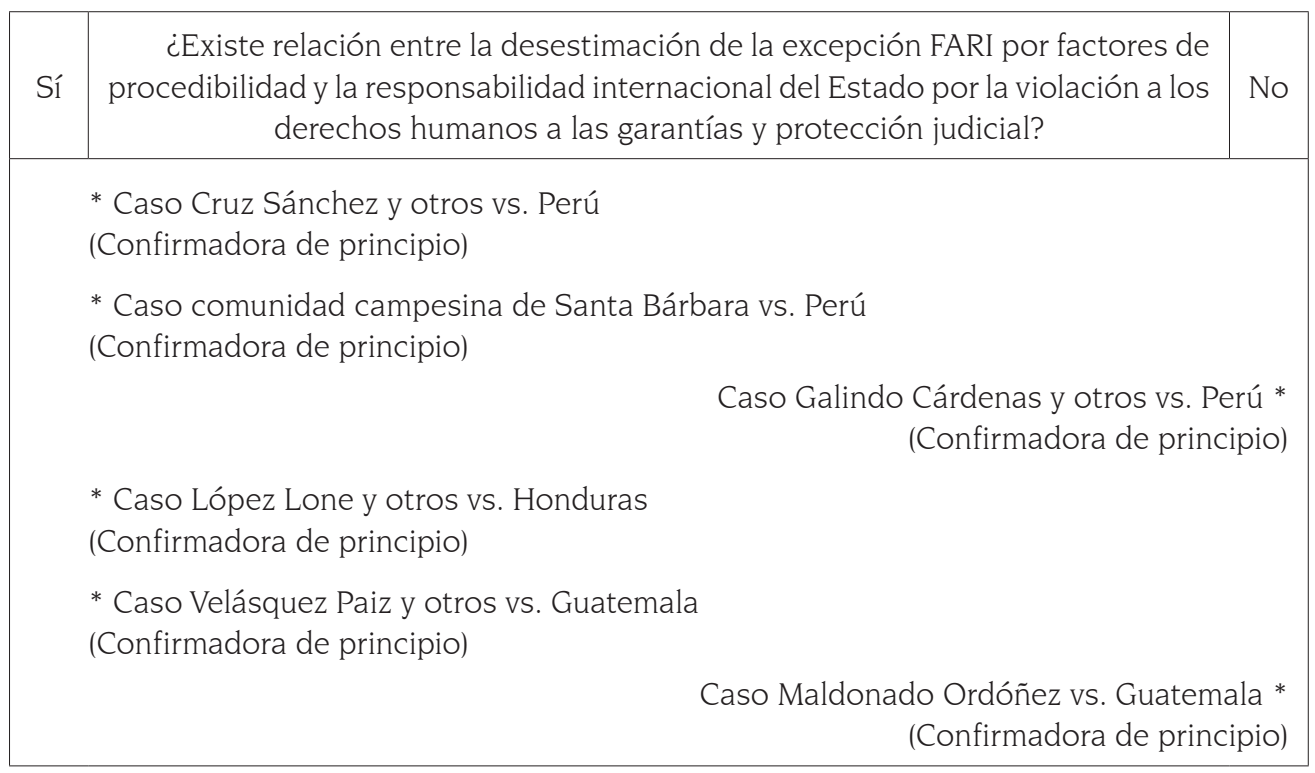

Fuente: elaboración propia a partir de las sentencias de excepciones preliminares y fondo emitidas por la Corte Interamericana de Derechos Humanos entre los años 2010 a 2016.

\section{CONCLUSIONES}

Con la creación de la línea jurisprudencial se logra determinar que en las sentencias de la Corte IDH emitidas en el espacio temporal 2010-2016, la hipótesis planteada se revierte porque el hecho de que declare improcedente la excepción preliminar de falta de agotamiento de los recursos internos, no implica necesariamente determinar por anticipado la responsabilidad internacional por las violaciones a los derechos humanos a las garantías judiciales y protección judicial.

En los casos bajo estudio, se identificó que la Corte Interamericana de Derechos Humanos, cuando va a estudiar la excepción preliminar de la falta de agotamiento de los recursos internos, hace la revisión de los requisitos procesales creados jurisprudencialmente para que la excepción pueda ser interpuesta en instancia de la Corte IDH, lo cual es un control formal y genera que no se logre hacer un análisis detallado de los recursos interpuestos por el Estado. Por lo que se podría decir, que el estudio de admisibilidad o no de la excepción a partir de los recursos alegados, su idoneidad y efectividad queda solamente en la etapa de la Comisión Interamericana. Lo cual puede ser considerado como garantía a la seguridad jurídica de las víctimas que acuden ante el Sistema Interamericano para la protección de sus derechos humanos, naturaleza y fin de este. 
De otro lado, se podría plantear que aun cuando pueden existir los recursos internos adecuados y efectivos en el Estado Parte, si el alegato no cumple con los requisitos de procedibilidad ante la Corte IDH, se antepone la seguridad jurídica y protección de las víctimas sobre los principios internacionales de subsidiariedad y complementariedad con los que cuenta el Estado.

Lo anterior permite señalar que no siempre cuando es desestimada la excepción preliminar de la falta de agotamiento de los recursos internos, existe una relación directa con la declaración de la responsabilidad internacional de un Estado por la violación a los derechos humanos de las garantías judiciales y protección judicial. Aunque es pertinente señalar que existe una interacción constante entre la excepción y el fondo del asunto, que se determina a partir de las particularidades de cada caso y que se puede identificar como se explica a continuación.

Cuando la excepción es desestimada porque la Corte hace un estudio detallado del recurso planteado por el Estado y determina que el mismo no cumple con los requisitos de adecuado o efectivo (Corte IDH, 2011b; 2012b; 2015c), o cuando logra identificar que se encuentra alguna causal del 46. 2 como el retardo injustificado en las decisiones (Corte IDH, 2013a, 2015b), la Corte retoma el argumento que realizó para desestimar la excepción y lo incluye en el fondo del asunto para declarar la responsabilidad del Estado por la violación a los derechos humanos a las garantías judiciales o protección judicial, demostrando así, una interacción directa.

Cuando la excepción es desestimada porque el Estado ha planteado un reconocimiento total o parcial de la responsabilidad internacional por la violación de los derechos humanos a las garantías judiciales y protección judicial, existe una relación directa de la excepción de falta de agotamiento de los recursos internos con el análisis que realiza la Corte IDH de estos derechos en el fondo dela decisión. Debido a que el Tribunal, por obvias razones, no evalúa los recursos alegados por el Estado en la excepción, pero sí los tiene en cuenta para complementar y sustentar los argumentos hechos por el reconcomiendo del Estado para declarar la responsabilidad internacional del mismo por la violación a los derechos humanos de garantías judiciales y protección judicial (Corte IDH, 2013b; 2015a; 2015d; 2015f), excepto en el caso de la masacre de Santo Domingo, en la cual, a pesar del reconocimiento del Estado, la Corte IDH declaró el cumplimiento de sus obligaciones convencionales (2012d).

Cuando la excepción es desestimada por no cumplir con los requisitos de procedibilidad, ya sea por extemporaneidad en la presentación por no haberla interpuesto ante la Comisión o por no cumplir en dicha oportunidad, el deber de mencionar y especificar los recursos adecuados y efectivos con los que contaba el Estado, no habrá relación ni interacción con el fondo del asunto si los recursos alegados en la Corte 
Interamericana no permiten inferir que tendrán la calidad de adecuados y efectivos para resolver la situación jurídica infringida objeto del litigio (Corte IDH, 2010; 2011a; 2012c; 2013a; 2014c; 2015e; 2016). De manera contraria, si la Corte identifica que los recursos alegados por el Estado en la excepción preliminar tienen una relación con los derechos presuntamente violados, ella los analiza y considera para declarar o no la responsabilidad del Estado por la violación a los derechos humanos a las garantías judiciales y protección judicial (Corte IDH, 2012a; 2014b; 2015c; 2015f), lo que demuestra una interacción entre la excepción y el fondo del asunto.

Por tanto, para la Corte IDH no es relevante que el Estado mencione una serie de recursos en la excepción, si estos no tienen relación directa con los derechos presuntamente vulnerados (Corte IDH, 2013c) o no son adecuados y efectivos, situación en la cual podrá realizar una interacción entre la excepción y el fondo del asunto.

Por último, si bien es cierto que el propósito de la investigación se centró sobre el análisis de la unión de la excepción preliminar falta de agotamiento de los recursos internos y su unión o interacción con los derechos humanos a las garantías judiciales y protección judicial, es pertinente mencionar que dicha interacción no se presenta solo con estos derechos. A lo largo del análisis jurisprudencial se logró identificar que la Corte Interamericana lo hace con otros derechos humanos protegidos por la Convención Americana como la integridad personal (Corte IDH, 2014b), la libertad personal (Corte IDH, 2014b;), la libertad de pensamiento y expresión (Corte IDH, 2013a; 2015d) y la propiedad privada (Corte IDH, 2013a; 2015b) los cuales podrán ser objeto de estudio en otra investigación.

\section{REFERENCIAS}

Barbosa, F. (2002). Litigio interamericano: perspectiva jurídica del sistema de protección de derechos humanos. Bogotá: Universidad Jorge Tadeo Lozano.

Comisión Interamericana de Derechos Humanos. CIDH. (2009). Informe de Inadmisibilidad n. 39/09. Petición 717-00. Tomás Eduardo Jiménez Villada vs. Argentina.

Comisión Interamericana de Derechos Humanos. CIDH. (2017) Informe de Inadmisibilidad n. ${ }^{\circ}$ 171/17. Petición 1454 07. María Del Carmen Camargo Romero vs. Colombia.

Corte Internacional de Justicia. (1959). Interhandel case (Switzerland vs. United States of America), Preliminary Objetions. Sentencia del 21 de marzo de 1959.

Corte Interamericana de Derechos Humanos. (1987a). Caso Velásquez Rodríguez vs. Honduras. Excepciones preliminares. Sentencia de 26 de junio de 1987. Serie C No. 1.

Corte Interamericana de Derechos Humanos. (1987b). Caso Fairén Garbi y Solís Corrales vs. Honduras. Excepciones preliminares. Sentencia de 26 de junio de 1987. Serie C No. 2. 
Corte Interamericana de Derechos Humanos. (1990) Excepciones al agotamiento de los recursos internos (artículos 46.1, 46.2. ay 46.2. b, Convención Americana sobre Derechos Humanos). Opinión consultiva OC-11/90 del, 10, 56616-2002.

Corte Interamericana de Derechos Humanos. (1996). Caso Castillo Páez vs. Perú. Excepciones preliminares. Sentencia de 30 de enero de 1996. Serie C No. 24.

Corte Interamericana de Derechos Humanos. (1998). Caso Castillo Petruzzi y otros vs. Perú. Excepciones preliminares. Sentencia de 4 de septiembre de 1998. Serie C No. 41.

Corte Interamericana de Derechos Humanos. (1999). Corte IDH. Caso Castillo Petruzzi y otros vs. Perú. Fondo, reparaciones y costas. Sentencia de 30 de mayo de 1999. Serie C No. 52.

Corte Interamericana de Derechos Humanos. (2002). Caso Cantos vs. Argentina. Fondo, reparaciones y costas. Sentencia de 28 de noviembre de 2002. Serie C No. 97.

Corte Interamericana de Derechos Humanos. (2005a). Caso de la "masacre de Mapiripán" vs. Colombia. Excepciones preliminares. Sentencia 7 de marzo 2005. Serie C No. 122.

Corte Interamericana de Derechos Humanos. (2005b). Caso Yatama vs. Nicaragua. Excepciones preliminares, fondo, reparaciones y costas. Sentencia de 23 de junio de 2005. Serie C No. 127.

Corte Interamericana de Derechos Humanos. (2006). Caso Acevedo Jaramillo y otros vs. Perú. Excepciones preliminares, fondo, reparaciones y costas. Sentencia de 7 de febrero de 2006. Serie C No. 144.

Corte Interamericana de Derechos Humanos. (2007). Caso García Prieto y otro vs. El Salvador. Excepciones preliminares, fondo, reparaciones y costas. Sentencia de 20 de noviembre de 2007. Serie C No. 168.

Corte Interamericana de Derechos Humanos. (2008a). Caso Salvador Chiriboga vs. Ecuador. Excepción preliminar y fondo. Sentencia de 6 de mayo de 2008. Serie C No. 179.

Corte Interamericana de Derechos Humanos. (2008b). Caso Heliodoro Portugal vs. Panamá. Excepciones preliminares, fondo, reparaciones y costas. Sentencia de 12 de agosto de 2008. Serie C No. 186.

Corte Interamericana de Derechos Humanos. (2009a). Caso Anzualdo Castro vs. Perú. Excepción preliminar, fondo, reparaciones y costas. Sentencia de 22 de septiembre de 2009. Serie C No. 202.

Corte Interamericana de Derechos Humanos. (2009b). Caso Garibaldi vs. Brasil. Excepciones preliminares, fondo, reparaciones y costas. Sentencia de 23 de septiembre de 2009. Serie C No. 203.

Corte Interamericana de Derechos Humanos. (2010). Caso Vélez Loor vs. Panamá. Excepciones preliminares, fondo, reparaciones y costas. Sentencia de 23 de noviembre de 2010 Serie C No. 218

Corte Interamericana de Derechos Humanos. (2011a). Caso Chocrón Chocrón vs. Venezuela. Excepción preliminar, fondo, reparaciones y costas. Sentencia de 1 de julio de 2011. Serie C No. 227. 
Corte Interamericana de Derechos Humanos. (2011b). Caso Mejía Idrovo vs. Ecuador. Excepciones preliminares, fondo, reparaciones y costas. Sentencia de 5 de julio de 2011 Serie C No. 228.

Corte Interamericana de Derechos Humanos. (2012a). Caso González Medina y familiares vs. República Dominicana. Excepciones preliminares, fondo, reparaciones y costas. Sentencia de 27 de febrero de 2012 Serie C No. 240.

Corte Interamericana de Derechos Humanos. (2012b). Caso Furlan y familiares vs. Argentina. Excepciones preliminares, fondo, reparaciones y costas. Sentencia de 31 de agosto de 2012. Serie C No. 246

Corte Interamericana de Derechos Humanos. (2012c). Caso Artavia Murillo y otros (fecundación in vitro) vs. Costa Rica. Excepciones preliminares, fondo, reparaciones y costas. Sentencia de 28 noviembre de 2012 Serie C No. 257

Corte Interamericana de Derechos Humanos. (2012d). Caso masacre de Santo Domingo vs. Colombia. Excepciones preliminares, fondo y reparaciones. Sentencia de 30 de noviembre de 2012. Serie C No. 259

Corte Interamericana de Derechos Humanos. (2013a). Caso Mémoli vs. Argentina. Excepciones preliminares, fondo, reparaciones y costas. Sentencia de 22 de agosto de 2013. Serie C No. 265

Corte Interamericana de Derechos Humanos. (2013b). Caso de la Corte Suprema de Justicia (Quintana Coello y otros) vs. Ecuador. Excepción preliminar, fondo, reparaciones y costas. Sentencia de 23 de agosto de 2013. Serie C No. 266 Condena parcialmente por garantías judiciales

Corte Interamericana de Derechos Humanos. (2013c). Caso familia Pacheco Tineo vs. Bolivia. Excepciones preliminares, fondo, reparaciones y costas. Sentencia de 25 de noviembre de 2013. Serie C No. 272

Corte Interamericana de Derechos Humanos. (2014b). Caso hermanos Landaeta Mejías y otros vs. Venezuela. Excepciones preliminares, fondo, reparaciones y costas. Sentencia de 27 de agosto de 2014. Serie C No. 281

Corte Interamericana de Derechos Humanos. (2014c). Caso de los pueblos indígenas Kuna de Madungandí y Emberá de Bayano y sus miembros Vs. Panamá. Excepciones preliminares, fondo, reparaciones y costas. Sentencia de 14 de octubre de 2014. Serie C No. 284.

Corte Interamericana de Derechos Humanos. (2015a). Caso Cruz Sánchez y otros vs. Perú. Excepciones preliminares, fondo, reparaciones y costas. Sentencia de 17 de abril de 2015. Serie C No. 292. Condena parcialmente por garantías judiciales y protección judicial.

Corte Interamericana de Derechos Humanos. (2015b). Caso Granier y otros (Radio Caracas Televisión) vs. Venezuela. Excepciones preliminares, fondo, reparaciones y costas. Sentencia de 22 de junio de 2015. Serie C No. 293.

Corte Interamericana de Derechos Humanos. (2015c). Caso Gonzales Lluy y otros vs. Ecuador. Excepciones preliminares, fondo, reparaciones y costas. Sentencia de 01 de septiembre de 2015. Serie C No. 298. 
Corte Interamericana de Derechos Humanos. (2015d). Caso comunidad campesina de Santa Bárbara vs. Perú. Excepciones preliminares, fondo, reparaciones y costas. Sentencia de 01 de septiembre de 2015. Serie C No. 299

Corte Interamericana de Derechos Humanos. (2015e). Caso Galindo Cárdenas y otros vs. Perú. Excepciones preliminares, fondo, reparaciones y costas. Sentencia de 02 de octubre de 2015. Serie C No. 301.

Corte Interamericana de Derechos Humanos. (2015f). Caso López Lone y otros vs. Honduras. Excepción Preliminar, fondo, reparaciones y costas. Sentencia de 05 de octubre de 2015. Serie C No. 302

Corte Interamericana de Derechos Humanos. (2015g). Caso Velásquez Paiz y otros vs. Guatemala. Excepciones preliminares, fondo, reparaciones y costas. Sentencia de 19 de noviembre de 2015. Serie C No. 307

Corte Interamericana de Derechos Humanos. (2016). Caso Maldonado Ordóñez vs. Guatemala. Excepción preliminar, fondo, reparaciones y costas. Sentencia de 3 de mayo de 2016. Serie C No. 311.

Faúndez, L. H. (2004). El sistema interamericano de protección de los derechos humanos: aspectos institucionales y procesales. San José de Costa Rica: Instituto Interamericano de Derechos Humanos.

Faúndez, L. H. (2007). El agotamiento de los recursos internos en el sistema interamericano de protección de los derechos humanos. Caracas: Centro de Estudios de Derechos Humanos, Universidad Central de Venezuela.

González, S. A. (2010). La excepción preliminar falta de agotamiento de recursos internos ċun mecanismo efectivo de defensa estatal? Prolegómenos, Derechos y Valores, 13(26),245-265.

González, A., Sanabria, J. E. y Meléndez, M. I. (2018). Unión de la excepción preliminar falta de agotamiento de recursos internos con el fondo del asunto. Saber, Ciencia y Libertad,13(1), 62-87.

Paúl Díaz, Á. (2015). Análisis sistemático de la evaluación de la prueba que efectúa la Corte Interamericana de Derechos Humanos. Revista Chilena de Derecho, 42(1), 297-327.

López, D. (2008). El derecho de los jueces. (2 Ed.). Bogotá: Legis.

Organización de Estados Americanos. OEA. (1969). Convención Americana sobre Derechos Humanos. Suscrita en San José de Costa Rica el 22 de noviembre de 1969, en la Conferencia Especializada Interamericana sobre Derechos Humanos.

Santana, R. y de la Muela, A. M. (1978). El agotamiento de los recursos internos como requisito de la protección internacional del individuo. Valencia: Universidad de Valencia. Secretariado de Publicaciones.

Trindade, A. A. C. (1991). El agotamiento de los recursos internos en el Sistema Interamericano de Protección de los Derechos Humanos (Vol. 1). San José de Costa Rica: Instituto Interamericano de Derechos Humanos, Área de Promoción y Asistencia a ONG, Programa de Asistencia Técnica a ONG. 